Article

\title{
PP-Rotation, $P$-Inversion and Metathesis in Diphosphines Studied by DFT Calculations: Comments on Some Literature Conflicts
}

\author{
Adam D. Molloy, Goar Sánchez-Sanz * and Declan G. Gilheany * \\ Centre for Synthesis and Chemical Biology, School of Chemistry, University College Dublin, \\ Belfield, Dublin D4, Ireland; adam.molloy@ucd.ie \\ * Correspondence: goar.sanchez@ucd.ie (G.S.-S.); declan.gilheany@ucd.ie (D.G.G.); \\ Tel.: +353-1-524-1608 (G.S.-S.); +353-1-716-2308 (D.G.G.) \\ Academic Editor: Lee J. Higham \\ Received: 27 September 2016; Accepted: 4 November 2016; Published: 18 November 2016
}

\begin{abstract}
The potential energy surface for internal rotation about the phosphorus-phosphorus

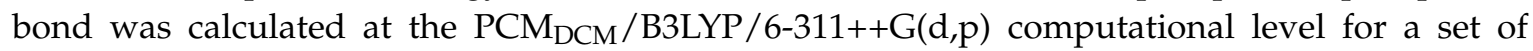
eight symmetrical, unsymmetrical and $P$-stereogenic diphosphines; $\mathrm{H}_{4} \mathrm{P}_{2}, \mathrm{Me}_{4} \mathrm{P}_{2},\left(\mathrm{CF}_{3}\right)_{4} \mathrm{P}_{2}, \mathrm{Ph}_{4} \mathrm{P}_{2}$, $\mathrm{Me}_{2} \mathrm{P}-\mathrm{P}\left(\mathrm{CF}_{3}\right)_{2}, \mathrm{Me}_{2} \mathrm{P}-\mathrm{PPh}_{2}$, and the meso- and $d l$-isomers of $\mathrm{Me}\left(\mathrm{CF}_{3}\right) \mathrm{P}-\mathrm{PMe}\left(\mathrm{CF}_{3}\right)$ and $\mathrm{MePhP}-\mathrm{PMePh}$. Certain trends in the data were elucidated and compared with conflicting data from the literature regarding the relative population of anti and gauche rotational isomers. The pyramidal inversion barriers (stereomutation barriers in P-stereogenic cases) for the same set of diphosphines was estimated through the inversion transition states and also compared to literature values. Finally, the $\mathrm{Me}_{4} \mathrm{P}_{2}+\left(\mathrm{CF}_{3}\right)_{4} \mathrm{P}_{2} \rightarrow 2 \mathrm{Me}_{2}\left(\mathrm{CF}_{3}\right)_{2} \mathrm{P}_{2}$ metathesis reaction was also explored to evaluate its feasibility versus inversion. The finding of larger barriers in the metathesis than in the inversion rules in favour of an inversion mechanism for the stereomutation of $P$-stereogenic diphosphines.
\end{abstract}

Keywords: diphosphines; PP-rotation; P-inversion; metathesis; DFT calculations

\section{Introduction}

P-Stereogenic diphosphines of the form $\left(\mathrm{R}^{1} \mathrm{R}^{2} \mathrm{P}\right)_{2}$ exist in meso- and dl-diastereomeric forms in solution with separate Nuclear Magnetic Resonance (NMR) spectra observable by ${ }^{1} \mathrm{H},{ }^{13} \mathrm{C}$ and ${ }^{31} \mathrm{P}$ NMR spectroscopy [1-3]. The seminal work on the intrinsic P-stereolability of diphosphines was published by Lambert, Jackson and Mueller (LJM) in which two mechanisms were considered; pyramidal inversion of one phosphorus atom and metathesis self-reaction [4,5]. High temperature NMR data supported a mechanism of pyramidal inversion because the observed rate of stereomutation was independent of concentration and the derived barriers to stereomutation followed the expected pattern for a small series of compounds with electron donating/withdrawing para-substituents and were comparable to those reported for monophosphorus species [6].

Citing this work, and suggesting that the topic of $P$-stereolability of diphosphines needed to be revisited, McFarlane and McFarlane (MM) reported a scrambling reaction for mixtures of diphosphines [7]. An apparent aggregation of diphosphines in high concentration polar solvents and the formation of unsymmetrical diphosphines in mixtures of symmetrical diphosphines supported an active metathesis pathway previously dismissed by LJM. This scrambling reaction typically results in a mixture of symmetrical and unsymmetrical diphosphines [8] but some polarized diphosphines were found to be "metathesis stable" and select mixtures yielded complete conversion to unsymmetrical diphosphine [3,9-11]. The use of the scrambling reaction fell out of favour because the stable unsymmetrical diphosphines could be more readily prepared by direct cross coupling of monophosphorus species. However, the idea of a four-membered metathesis mechanism was invoked 
for other reactions involving diphosphines [12-14]. It is also important to note that diphosphines can undergo other rapid exchange reactions with cleavage of the P-P bond [15] such as those with secondary phosphines $[13,14]$, halophosphines, metal phosphides and $\mathrm{HCl}[14,15]$ which may remain in solution as minor impurities from the preparation of the diphosphine itself. Thus any measurement of the stereolability of diphosphines is suspect.

Related to the above are conflicting conclusions that were also derived from several techniques employed in the investigation of another dynamic process of diphosphines in solution: rotational isomerisation about the P-P bond. Borisenko and Rankin [16] summarised the conflicting literature data for the case of tetramethyldiphosphine and their summary is given in Table 1. Further to their work on the homolytic cleavage of the phosphorus-phosphorus bond, they employed a variety of computational techniques (HF, MP2, B3LYP) to investigate rotational isomerisation about the P-P bond. Notably, they showed that B3LYP, even using small basis sets $\left(3-21 \mathrm{G}^{*}\right)$ allowed quick, reliable estimations "on a par" with calculations using more computationally expensive techniques. Notions of exotic behaviour in the P-P bond were dispelled by the similarity of the calculated potential energy curve for internal rotation in tetramethyldiphosphine to that of $n$-butane [17].

Table 1. Conflicting conclusions from literature regarding the rotational configuration of $\mathbf{2}^{\mathrm{a}}$.

\begin{tabular}{ll}
\hline \multicolumn{1}{c}{ Technique } & \multicolumn{1}{c}{ Conclusion } \\
\hline Raman spectroscopy [18] & 60:40 gauche:anti (liquid) \\
IR spectroscopy [19] & 60:40 gauche:trans \\
Electron diffraction & exclusively distorted trans \\
Photoelectron spectroscopy & 16:84 gauche:trans \\
VT PE spectroscopy & trans more stable than gauche $2.1 \pm 0.4 \mathrm{~kJ} / \mathrm{mol}$ \\
MS fragmentation analysis & exclusively trans \\
Computational & trans more stable than gauche $6.1 \mathrm{vs.} 5.4 \mathrm{~kJ} / \mathrm{mol}$ : \\
\hline
\end{tabular}

a Adapted from Borisenko and Rankin [16].

Despite further reports from both teams, the initial contradiction between LJM's and MM's observations has not been fully addressed. With the aim of reconciling these apparently conflicting reports, we followed the approach of Borisenko and Rankin but using a higher computational level B3LYP / 6-311++G(d,p) including solvation effects, the work-horse computational technique used to support organic synthesis, to estimate the energetics for the three observed dynamic processes of suitable diphosphines (Scheme 1): internal rotation around the P-P bond, pyramidal inversion at one phosphorus centre and metathesis self-reaction.

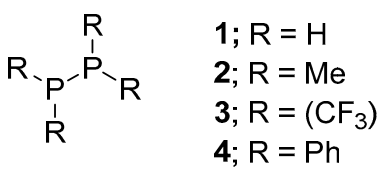

$$
\begin{aligned}
& \begin{aligned}
R^{R^{2}} & \text { 5; } R^{1}=M e, \\
R^{1}-P_{-}^{2} & =\left(\mathrm{CF}_{3}\right)
\end{aligned} \\
& \mathrm{R}^{1} \\
& \text { 6; } \mathrm{R}^{1}=\mathrm{Me} \text {, } \\
& \mathrm{R}^{2}=\mathrm{Ph} \\
& \begin{array}{rlrl}
R^{1} & 7 ; R^{1} & =M e, \\
R^{1} P^{1} & =\left(\mathrm{CF}_{3}\right) \\
\mathrm{P}_{-}-R^{2} & \mathbf{8} ; R^{1} & =\mathrm{Me}, \\
\mathrm{R}^{2} & & \mathrm{R}^{2} & =\mathrm{Ph}
\end{array}
\end{aligned}
$$

Scheme 1. Symmetrical $(\mathbf{1}, \mathbf{2}, \mathbf{3}, \mathbf{4})$, unsymmetrical $(5,6)$ and $P$-stereogenic diphosphines $(\mathbf{7}, \mathbf{8})$ studied in this work. 


\section{Results and Discussion}

\subsection{Rotational Isomerization}

The potential energy curve for rotation around the P-P bond was calculated by constraining the dihedral angle between substituents of different phosphorus atoms. Thus the $\mathrm{C}_{2 \mathrm{~h}}$ symmetrical anti conformer and the $C_{2}$ symmetrical syn conformer occur at a dihedral angle of $180^{\circ}$ and $0^{\circ} / 360^{\circ}$, respectively (Scheme 2). In order to obtain a benchmark and justify the methodology chosen, we obtained the curve calculated for the symmetrical diphosphines $\mathrm{H}_{4} \mathrm{P}_{2} \mathbf{1}$ and Me4P2 2 at both MP2 and B3LYP gas phase computational level using the $6-311+G(d, p)$ basis set.<smiles>[2H]P([2H])[2H]</smiles>

syn

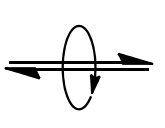

\section{H}

(1)<smiles>[H][Y]P</smiles>

gauche

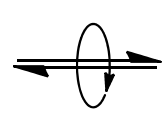<smiles>[2H][PH2]([3H])C</smiles>

anti

Scheme 2. Rotational conformations of diphosphine $\mathbf{1 .}$

As plotted in Figure S1 (Supplementary Materials), the MP2 and B3LYP methods describe the same potential energy surface for each system selected, with small differences in the transition barriers of ca. 2 and $6 \mathrm{~kJ} \cdot \mathrm{mol}^{-1}$ for $\mathrm{H}_{4} \mathrm{P}_{2}$ and $\mathrm{Me}_{4} \mathrm{P}_{2}$, respectively. The MP2 method is more computationally demanding and particularly in large systems, is unaffordable. In the light of the Figure S1 results, we believe that the B3LYP method will produce reliable results with respect to the more accurate MP2 results with a reasonable computational cost. This also is in agreement what was found by Azofra, et al. [20].

Furthermore, we also evaluated the solvent effect in both $\mathrm{H}_{4} \mathrm{P}_{2}$ and $\mathrm{Me}_{4} \mathrm{P}_{2}$. Figure S2 shows the curves obtained at the B3LYP/6-311+G(d,p) gas-phase, PCM-Water and PCM-DCM level. The solvent model had little effect on the energy barriers in the $\mathrm{H}_{4} \mathrm{P}_{2}$ systems. However, the transition barriers for the $\mathrm{Me}_{4} \mathrm{P}_{2}$ present larger reductions compared to the gas phase results. Thus, we proceeded on the basis that all the calculations considered were performed at the B3LYP level under the PCM-DCM solvation model. However, to increase the accuracy a slightly larger basis set, 6-311++G(d,p) was used for all the calculations. It is worth noting that dispersion effects may be negligible in the smallest systems, such as $\mathrm{H}_{4} \mathrm{P}_{2}$ while in larger systems like $\mathrm{Me}_{4} \mathrm{P}_{2}$, such effects can be more appreciable. In order to verify our choice of computational method, we also optimised the anti and gauche minima of the $\mathrm{H}_{4} \mathrm{P}_{2}, \mathrm{Me}_{4} \mathrm{P}_{2}$, and $\left(\mathrm{CF}_{3}\right)_{4} \mathrm{P}_{2}$ systems using the M06-2X functional which accounts for long range dispersions with 6-311++G(d,p) and Dunning's correlation consistent aug-cc-pVTZ basis set. As observed in Table S1, the differences in the relative energies across the methods do not exceed $2 \mathrm{~kJ} \cdot \mathrm{mol}^{-1}$. This shows that the computational level selected is a good compromise between accuracy and computational cost.

The potential energy surfaces corresponding to the studied compounds have been obtained and the critical points, i.e., maxima and minima structures, have been identified. In all cases, the minima and maxima structures were optimized and frequency calculations carried out to confirm that those structures correspond to true minima (no negative frequencies) or to transition states (one imaginary frequency connecting two minima). In Table 2, the Gibbs free energies, $(\Delta G)$ in $\mathrm{kJ} \cdot \mathrm{mol}^{-1}$ of each structure have been gathered together. 
Table 2. Gibbs free energies, $(\Delta G)$ in $\mathrm{kJ} \cdot \mathrm{mol}^{-1}$ of compounds $\mathbf{1 - 8}$ in various conformations ${ }^{\text {a }}$.

\begin{tabular}{|c|c|c|c|c|c|c|c|}
\hline Compound & Compound & $a n t i^{b}$ & eclipsed (TS) ${ }^{c}$ & gauche $^{\mathrm{b}}$ & $\operatorname{syn}(T S)^{c}$ & & \\
\hline $\mathrm{H}_{4} \mathrm{P}_{2}$ & 1 & 0.0 & 3.9 & 0.9 & 15.0 & & \\
\hline $\mathrm{Me}_{4} \mathrm{P}_{2}$ & 2 & 0.0 & 13.0 & 4.4 & 29.8 & & \\
\hline$\left(\mathrm{CF}_{3}\right)_{4} \mathrm{P}_{2}$ & 3 & 0.0 & 7.7 & 1.5 & 45.9 & & \\
\hline $\mathrm{Ph}_{4} \mathrm{P}_{2}$ & 4 & 0.0 & 22.8 & 11.1 & 52.6 & & \\
\hline $\mathrm{Me}_{2} \mathrm{P}-\left(\mathrm{CF}_{3}\right)_{2} \mathrm{P}$ & 5 & 1.0 & 11.0 & 0.0 & 31.2 & & \\
\hline $\mathrm{Me}_{2} \mathrm{P}-\mathrm{Ph}_{2} \mathrm{P}$ & 6 & 0.0 & 13.6 & 5.9 & 42.9 & & \\
\hline $\mathrm{Me}\left(\mathrm{CF}_{3}\right) \mathrm{P}-\mathrm{P}\left(\mathrm{CF}_{3}\right) \mathrm{Me}$ & 7-meso & 0.0 & 9.1 & 2.8 & 41.4 & & \\
\hline MePhP-PPhMe & 8-meso & 0.0 & 15.2 & 4.5 & 37.4 & & \\
\hline Compound & Compound & anti & eclipsed (R) & gauche (R) & syn & $\begin{array}{l}\text { gauche } \\
\text { (Me) }\end{array}$ & $\begin{array}{l}\text { eclipsed } \\
\text { (Me) }\end{array}$ \\
\hline $\mathrm{Me}\left(\mathrm{CF}_{3}\right) \mathrm{P}-\mathrm{P}\left(\mathrm{CF}_{3}\right) \mathrm{Me}$ & $7-d l$ & 1.1 & 23.7 & 8.6 & 35.7 & 0.0 & 5.1 \\
\hline MePhP-PPhMe & 8-dl & 0.0 & 16.2 & 4.1 & 29.5 & 5.3 & 17.6 \\
\hline
\end{tabular}

From Table 2, it can be seen that the symmetrical diphosphines 1-4 present the same general trend, with three local minima of comparable energy corresponding to the anti and two degenerate gauche conformers. A global maximum occurs for the fully eclipsed syn conformer with local maxima associated with the eclipsing transition state between anti and gauche conformers. While in each case, the global minimum corresponds to the anti conformer, in $\mathbf{1}$ and $\mathbf{3}$ the difference from the gauche is slight ( 0.9 and $\left.1.5 \mathrm{~kJ} \cdot \mathrm{mol}^{-1}\right)$, whereas in 2 and 4 the difference is larger, $\left(4.4\right.$ and $11.1 \mathrm{~kJ} \cdot \mathrm{mol}^{-1}$, respectively). The difference in the relative energies between anti and gauche conformers arise mainly from interaction between the $R$ groups. As stated before, the long-range dispersion term might also have an important role, particularly in 3 and 4 , where $R$ groups are larger and may interact between them. It was shown (Table S1) that an increase of the basis set or even the use of M06-2X functional, which accounts for long-range dispersion, slightly increased the difference, but still within a range of $2 \mathrm{~kJ} \cdot \mathrm{mol}^{-1}$.

The P-P bond length is overestimated for both $\mathbf{1}$ (2.252 and 2.268 Å for gauche and anti, respectively) and 2 (2.244 and $2.254 \AA$ for gauche and anti, respectively), whose bond lengths have been measured at $2.219 \AA$ (gas electron diffraction) and $2.212 \AA$ (X-ray diffraction), respectively [21,22]. Azofra, et al. also obtained the P-P distance for 1-gauche (2.220 A) at the MP2/aug-cc-pVTZ computational level [20], while Katsyuba et al. [23] performed calculations of $\mathrm{H}_{4} \mathrm{P}_{2}$ and $\mathrm{Me}_{4} \mathrm{P}_{2}$ at different computational levels, HF/aug-cc-pVTZ, B3PW91/aug-cc-pVTZ and BPW91/cc-pVTZ finding P-P distances of 2.422 and $2.231 \AA$ for $\mathbf{1}$ and $\mathbf{2}$ respectively at the most accurate level (B3PW91/aug-cc-pVTZ). Although there is an overestimation of the P-P distances by the B3LYP hybrid functional, the agreement between our computational data and the other theoretical methods (such MP2) and the experimental measurements is quite good. The calculated barrier between anti and gauche for 2 is $13.3 \mathrm{~kJ} \cdot \mathrm{mol}^{-1}$ in keeping with the lack of visible rotational isomers in NMR spectra as low as $-65{ }^{\circ} \mathrm{C}$ [24]. A local contraction of the P-P bond length is associated with the two gauche conformers, and to a lesser extent the anti conformer. A notable increase in the estimated transition states between the anti and gauche conformers of 4 $\left(22.8 \mathrm{~kJ} \cdot \mathrm{mol}^{-1}\right)$ is attributed to steric effects. Similar effects were found in the experimental data of sterically hindered tetraalkyldiphosphines with large substituents [24].

The potential energy surface for the electron deficient diphosphine 3 deviates from the trend. The PES (Figure S3) shows two anti conformers connected by a symmetrical $\mathrm{C}_{2 \mathrm{~h}}$ transition state. The local maxima defining the transition state between anti and gauche conformers is less pronounced at $7.7 \mathrm{~kJ} \cdot \mathrm{mol}^{-1}$ compared to $13.0 \mathrm{~kJ} \cdot \mathrm{mol}^{-1}$ for $\mathrm{Me}_{4} \mathrm{P}_{2}$ and $22.8 \mathrm{~kJ} \cdot \mathrm{mol}^{-1}$ for $\mathrm{Ph}_{4} \mathrm{P}_{2}$. A destabilising effect is also observed for the anti conformer and apparent in a local elongation of the P-P bond length. The P-P bond length of the gauche conformers of $3(2.263 \AA)$ is in closer agreement with the 
literature data, $2.246 \AA$ (X-ray of solid), $2.25 \AA$ (electron diffraction) [22] and 2.259 $\AA$ (calculations at the B3PW91/aug-cc-pVTZ level) [23].

Cowley, et al. attributed signals in the photoelectron spectrum of tetramethyldiphosphine, 2, and tetrakis-(trifluoromethyl)diphosphine, 3, to anti and gauche rotamers [25] while Becker, et al. more recently studied the same compounds using gas phase electron diffraction [22]. Boltzmann distributions calculated from the rotational energy profiles presented here are in close agreement with the values reported from the photoelectron spectrum of $\mathbf{2}$ but are significantly different in the case of $\mathbf{3}$, summarised in Table 3.

Table 3. Comparison of calculated and experimental populations of anti and gauche conformers of compounds 1-4.

\begin{tabular}{ccc}
\hline Compound & $\begin{array}{c}\text { This Work: anti:gauche Boltzmann } \\
\text { Distribution at B3LYP/6-31G* }\end{array}$ & $\begin{array}{c}\text { Literature Values } \\
\text { anti:gauche }\end{array}$ \\
\hline $\mathrm{H}_{4} \mathrm{P}_{2}(\mathbf{1})$ & $59: 41$ & - \\
\hline $\mathrm{Me}_{4} \mathrm{P}_{2}(\mathbf{2})$ & $86: 14$ & $84: 16[25]$ \\
\hline$\left(\mathrm{CF}_{3}\right)_{4} \mathrm{P}_{2}(\mathbf{3})$ & $64: 36$ & $85: 15 \pm 10[22]$ \\
& $90: 10[25]$ \\
\hline $\mathrm{Ph}_{4} \mathrm{P}_{2}(\mathbf{4})$ & $99: 1$ & - \\
\hline
\end{tabular}

In the case of unsymmetrical diphosphines, $\mathrm{Me}_{2} \mathrm{X}_{2} \mathrm{P}_{2} \mathbf{5}$ and $\mathbf{6}$ similar scan profiles were found (Table 2) as those for 1, 2 and 4. However, while in $\mathrm{Me}_{2} \mathrm{P}-\mathrm{Ph}_{2} \mathrm{P}$ the anti conformer is predominant (by $\left.5.9 \mathrm{~kJ} \cdot \mathrm{mol}^{-1}\right)$, in $\mathrm{Me}_{2} \mathrm{P}-\left(\mathrm{CF}_{3}\right)_{2} \mathrm{P}$ it is the other way around. In fact, the transition barriers between anti and gauche conformers are larger in 6 than in $5\left(13.6\right.$ and $11.0 \mathrm{~kJ} \cdot \mathrm{mol}^{-1}$, respectively).

For each of the $P$-stereogenic diphosphines 7 and 8 , both the meso- and $d l$-diastereomers were modelled separately. The potential energy surface of 7-meso is symmetrical about the ant $i$ conformer with two degenerate gauche conformers, having a global minimum in the anti conformation with a transition barrier of $9.1 \mathrm{~kJ} \cdot \mathrm{mol}^{-1}$ between the anti and gauche conformers (Table 2). In contrast, the rotational energy profile of $7-d l$ is asymmetrical and shows a local minimum associated with the anti conformer slightly less stable $\left(1.1 \mathrm{~kJ} \cdot \mathrm{mol}^{-1}\right)$ than the gauche $(\mathrm{Me})$ conformer. It seems clear from these results and those of compounds $\mathbf{3}$ and $\mathbf{5}$ that the electron withdrawing trifluoromethyl group has a significant overall effect of lowering the differences between the anti and gauche conformers. Furthermore, the steric effect between the substituting groups plays also an important role, since in 3 it would present more steric repulsion than in 5 and therefore the barriers are expected to be larger in 3 than in 5.

The potential energy surface for 8-meso follows a similar trend to that of $\mathbf{2}$ and has comparable magnitude. The potential energy surface for 8- $d l$ is again unsymmetrical about the anti conformer, with three non-degenerate local minima, a global minimum associated with one gauche isomer (with semi-eclipsing phenyl groups). However, as in 7-dl, the anti conformer is very close in energy, only $0.4 \mathrm{~kJ} \cdot \mathrm{mol}^{-1}$ higher than the gauche conformer. This is consistent with the lack of rotational isomerisation observed for 8 by LJM for samples cooled as low as $-60{ }^{\circ} \mathrm{C}$ indicating gauche/anti barriers of less than $\sim 10 \mathrm{~kJ} \cdot \mathrm{mol}^{-1}$. Our calculated barriers are in the same range but slightly larger (at $289.15 \mathrm{~K}$ ). Rotational isomerisation was observed for tetraisopropyldiphosphine with an anti/gauche barrier of $12.5 \mathrm{~kJ} \cdot \mathrm{mol}^{-1}$ in a similar experiment [24].

\subsection{Stereomutation by Pyramidal Inversion}

To estimate the barrier to stereomutation by inversion of one phosphorus atom, the proposed transition state (with one planar phosphorus atom having all angle ca. $120^{\circ}$, Figure 1) was obtained and characterised by the presence of a negative (imaginary frequency) corresponding to the inversion of the phosphorus atom, leading to the barriers shown in Table 4. 


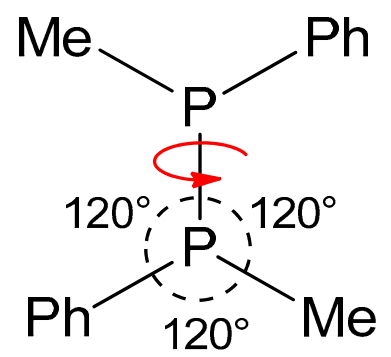

Figure 1. Constraining all three angles at phosphorus to $120^{\circ}$ forces a planar geometry, approximating the transition state for pyramidal inversion at one phosphorus centre. Red arrow indicates the rotation around the $\mathrm{P}-\mathrm{P}$ bond.

Table 4. $\Delta \mathrm{G}$ barrier, in $\mathrm{kJ} \cdot \mathrm{mol}^{-1}$, to pyramidal inversion at one phosphorus centre for $\mathbf{1}-\mathbf{8}$.

\begin{tabular}{|c|c|c|c|c|}
\hline Compound & Compound & Inversion (R) & & \\
\hline $\mathrm{H}_{4} \mathrm{P}_{2}$ & 1 & 110.7 & & \\
\hline $\mathrm{Me}_{4} \mathrm{P}_{2}$ & 2 & 114.0 & & \\
\hline$\left(\mathrm{CF}_{3}\right)_{4} \mathrm{P}_{2}$ & 3 & 100.9 & & \\
\hline $\mathrm{Ph}_{4} \mathrm{P}_{2}$ & 4 & 84.6 & & \\
\hline Compound & Compound & Inversion (R) & Inversion (Me) & \\
\hline $\mathrm{Me}_{2} \mathrm{P}-\left(\mathrm{CF}_{3}\right)_{2} \mathrm{P}$ & 5 & 106.4 & 100.8 & \\
\hline $\mathrm{Me}_{2} \mathrm{P}-\mathrm{Ph}_{2} \mathrm{P}$ & 6 & 86.5 & 106.9 & \\
\hline Compound & Compound & (R)-gauche-meso ${ }^{\mathrm{a}}$ & (R)-gauche (Me)-dl b & (R)-gauche $(X)-d l{ }^{\mathrm{c}}$ \\
\hline $\mathrm{Me}\left(\mathrm{CF}_{3}\right) \mathrm{P}-\mathrm{P}\left(\mathrm{CF}_{3}\right) \mathrm{Me}$ & 7 & 102.8 & 107.4 & 99.1 \\
\hline MePhP-PPhMe & 8 & 103.1 & 100.8 & 101.8 \\
\hline
\end{tabular}

As observed in Table 4, all the transition barriers are within a range of 84.6 to $114.0 \mathrm{~kJ} \cdot \mathrm{mol}^{-1}$. The lowest inversions are those corresponding to compounds 4 and $\mathbf{6}$. However, with the exception of those, the inversion barriers obtained present slight variations with the groups considered. In the particular case of $\mathbf{7}$ and $\mathbf{8}$, the interconversion between meso- and $d l$-conformers is almost invariant to which minimum is referred, i.e., barriers with respect to gauche-meso, gauche (Me)-dl and gauche-(R)-dl are within a range of 8.3 and $2.3 \mathrm{~kJ} \cdot \mathrm{mol}^{-1}$ for $\mathbf{7}$ and 8 .

As observed from the computational results, rotational barriers are much smaller than inversion barriers. The rotational barriers found vary from 3.9 to $52.6 \mathrm{~kJ} \cdot \mathrm{mol}^{-1}$ while the inversion barriers are within $84.6-110.7 \mathrm{~kJ} \cdot \mathrm{mol}^{-1}$. The most interesting case is 4 where the difference between rotational and inversion barrier is the smallest of all the compounds studies, since its rotational barrier accounts for $52.6 \mathrm{~kJ} \cdot \mathrm{mol}^{-1}$ and the inversion of the $P$ atom is $84.6 \mathrm{~kJ} \cdot \mathrm{mol}^{-1}$.

\subsection{Stereomutation by Metathesis Self-Reaction}

With the calculated inversion barriers in hand, we investigated the metathesis process to gain insight on the relative viability of each process. We chose the metathesis reaction of 1,1-dimethyl-2,2bis(trifluoromethyl)diphosphine, $\mathrm{Me}_{4} \mathrm{P}_{2}+\left(\mathrm{CF}_{3}\right)_{4} \mathrm{P}_{2} \rightarrow 2 \mathrm{Me}_{2}\left(\mathrm{CF}_{3}\right)_{2} \mathrm{P}_{2}$.

Our first model for the transition state was a square, 4-membered ring with $\mathrm{P}-\mathrm{P}$ bond lengths similar to those observed for the free diphosphines-in effect the union of two syn rotational conformers. However, all attempts to obtain a stable model were unsuccessful and the structures tended either to revert spontaneously to the reactants or to dissociate into two gauche conformers (products) during the geometry optimisation steps of the calculations.

The found potential energy surface corresponding to stable structures is depicted in Figure 2. The first transition state which connects the reactants with Min_1 corresponds to a distorted rhombic 
structure exhibiting a transition barrier of $\Delta G=152.7 \mathrm{~kJ} \cdot \mathrm{mol}^{-1}$. Min_1 itself is a non-symmetrical structure identified as a stable kite-shaped intermediate where the 4-membered ring has effectively dissociated into a three-phosphorus cation (natural atomic charges of $0.669,0.812$ and 0.509) and a single phosphorus anion (-0.082) separated by 3.624 and $3.368 \AA$, Figure 3. Min_1 evolves into a transition state located at $158.2 \mathrm{~kJ} \cdot \mathrm{mol}^{-1}$ with respect to the entrance channel with a barrier of $80.6 \mathrm{~kJ} \cdot \mathrm{mol}^{-1}$, in which the negative phosphorus moiety attacks the terminal phosphorus resulting in a semi-opened ring. This later evolves in a final step into the products, which are found to be $54.5 \mathrm{~kJ} \cdot \mathrm{mol}^{-1}$ more stable than the entrance channel.

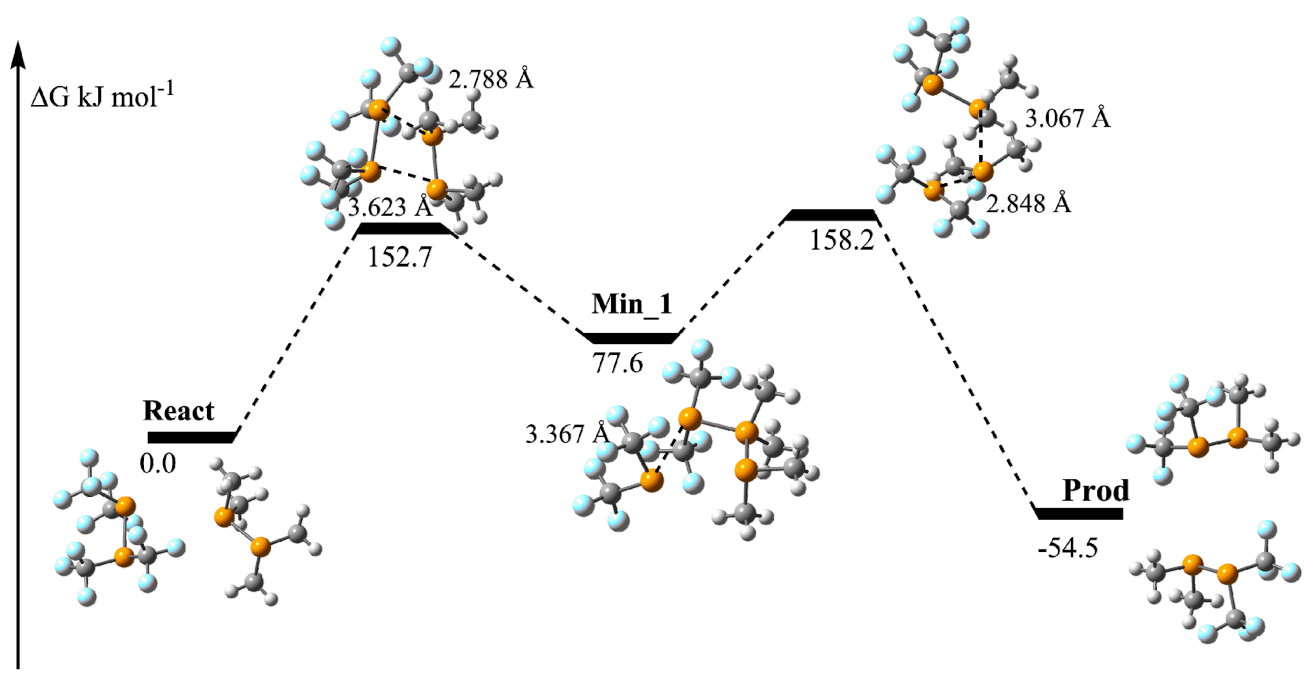

Figure 2. Potential energy surface corresponding to the metathesis of $\mathrm{Me}_{4} \mathrm{P}_{2}+\left(\mathrm{CF}_{3}\right)_{4} \mathrm{P}_{2} \rightarrow$ $2 \mathrm{Me}_{2}\left(\mathrm{CF}_{3}\right)_{2} \mathrm{P}_{2}$ at the $\mathrm{PCM} \mathrm{DCM}_{\mathrm{B}} / \mathrm{B} 3 \mathrm{LYP} / 6-311++\mathrm{G}(\mathrm{d}, \mathrm{p})$. Blue, orange, grey and white atoms corresponds to $\mathrm{F}, \mathrm{P}, \mathrm{C}$ and $\mathrm{H}$ atoms respectively.

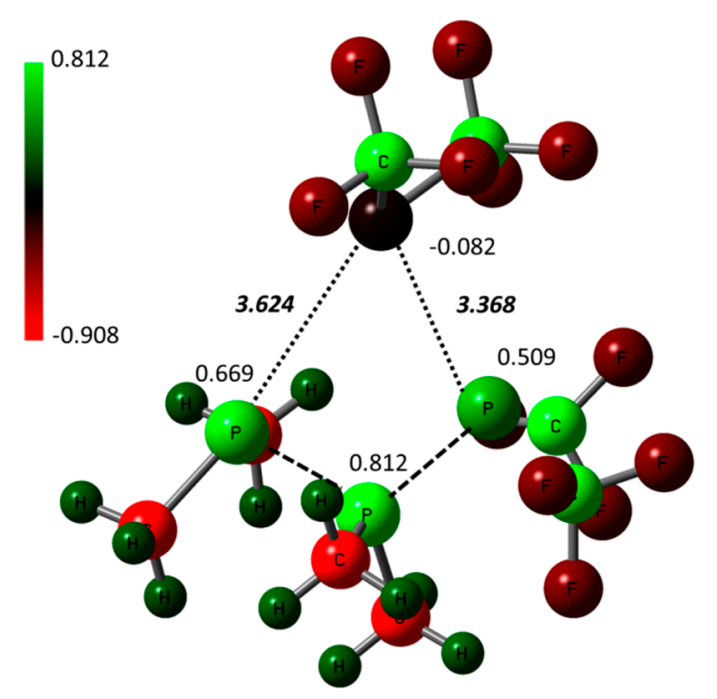

Figure 3. Natural Atomic Charges corresponding to the intermediate Min_1. P-P bond distances are labelled in bold (in $\AA$ ).

Jackson and Mueller (LJM) prepared their diphosphines by heating the corresponding diphosphine disulfide with copper dust and distilling directly into an NMR tube which was then sealed. Thus, all of their observations are for neat diphosphines (or in certain cases solutions with biphenyl as solvent to allow high temperature NMR experiments). They observed no aggregation, whereas MM saw aggregation and scrambling in polar solvents, typically dichloromethane. Thus a polar/ionic 
intermediate, active in polar solutions but disfavoured in the neat compound could explain the contradicting reports for 1,2-dimethyl-1,2-diphenyldiphosphine and play an important role in understanding and modeling the mechanism of diphosphine reactions.

However the data in Figure 2 shows that the metathesis reaction is not a feasible process due to the large transition barriers. The inversion barriers previously found indicate that the latter process is more viable than the metathesis, and therefore the process to convert meso to $d l$ is much more likely to be inversion. Thus for compound 5, inversion barriers were 100.8 and $106.4 \mathrm{k} \cdot \mathrm{Jmol}^{-1}$ for the inversion of the $\mathrm{Me}_{2} \mathrm{P}$ and $\left(\mathrm{CF}_{3}\right)_{2} \mathrm{P}$, respectively, while the transition barriers found for the metathesis reaction are at least $50 \%$ higher at 152.7 and $158.2 \mathrm{~kJ} \cdot \mathrm{mol}^{-1}$.

We must therefore assume that any observed metathesis is occurring via impurities in the system. It is fairly easy to envisage that in the presence of, for example, Bronsted acids, one of the phosphorus atoms can become a good leaving group so that nucleophilic attack at the other phosphorus can lead to the scrambling reactions observed.

\section{Methods}

All the scan geometries were obtained at the B3LYP /6-311+G(d,p) $[26,27]$ computational level. Second order Møller-Plesset perturbation theory (MP2) [28] with the 6-311+G(d,p) [29] was also considered to evaluate the performance of the DFT calculations in gas phase.

Full optimization of all the structures, including rotation isomerization structures, were carried out at the B3LYP/6-311++G $(\mathrm{d}, \mathrm{p})$ computational level. Harmonic vibrational frequencies were computed at the same level used in order to verify that the structures obtained correspond to local minima or maxima.

The effects of dichloromethane solvation were included by means of the Self-Consistent Reaction Field-Polarisable Continuum Model (SCFR-PCM) approaches implemented in the Gaussian-09 package including dispersing, repulsing, and cavitating energy terms of the solvent starting from the gas-phase geometries and re-optimizing.

The Natural Bond Orbital (NBO) method [30] was employed to evaluate atomic charges using the NBO-3.1 program, included within the Gaussian-09 program.

\section{Conclusions}

Quantum chemical calculations for the potential energy curves for internal rotation around the $\mathrm{P}-\mathrm{P}$ bond for tetramethyldiphosphine $\left(\mathrm{Me}_{4} \mathrm{P}_{2}\right)$ and tetrakis(trifluoromethyl)diphosphine $\left(\left(\mathrm{CF}_{3}\right)_{4} \mathrm{P}_{2}\right)$ showed good agreement with the photoelectron spectroscopy and Raman data for the occupancy of gauche and anti conformers at ambient temperature. Additionally, the calculated relative energies between the most stable structures in meso and $d l$ conformers for compounds $\mathbf{7}$ and $\mathbf{8}$ also are in reasonable agreement with the ratios measured by NMR.

The computationally obtained barrier to $P$-stereomutation by pyramidal inversion at one phosphorus centre also showed good agreement with the observed barriers to stereomutation reported by Lambert, Jackson and Mueller for $\mathrm{Me}_{4} \mathrm{P}_{2}$ and $\left(\mathrm{CF}_{3}\right)_{4} \mathrm{P}_{2}$ compounds.

The $\mathrm{Me}_{4} \mathrm{P}_{2}+\left(\mathrm{CF}_{3}\right)_{4} \mathrm{P}_{2} \rightarrow 2 \mathrm{Me}_{2}\left(\mathrm{CF}_{3}\right)_{2} \mathrm{P}_{2}$ metathesis reaction was found to occur via a kite-shaped intermediate when modelled with implicit polar solvents resulting in a complete dissociation into a three-phosphorus-unit cation and a one-phosphorus-unit anion. The first transition state for this process corresponds to a distorted rhombic structure with a barrier amounting to $\Delta G=152.7 \mathrm{~kJ} \cdot \mathrm{mol}^{-1}$, a much larger barrier than the inversion process. We interpret this to indicate that the previously observed "metathesis" and scrambling reactions are more complex than previously proposed and probably involve the intervention of other species present from the reactions used to generate the diphosphines.

Supplementary Materials: The following are available online at www.mdpi.com/2304-6740/4/4/36/s1, Figure S1: PES for $\mathrm{H}_{4} \mathrm{P}_{2}$ and $\mathrm{Me}_{4} \mathrm{P}_{2}$, corresponding to the rotation along the molecular axis, at the MP2 and B3LYP / 6-311++G(d,p) computational levels in gas phase, Figure S2: PES for $\mathrm{H}_{4} \mathrm{P}_{2}$ and $\mathrm{Me}_{4} \mathrm{P}_{2}$, corresponding to 
the rotation along the molecular axis and B3LYP/6-311+G(d,p), gas phase, PCM-Water and PCM-DCM, Figure S3: PES for $\left(\mathrm{CF}_{3}\right)_{4} \mathrm{P}_{2}$ corresponding to the rotation along the molecular axis and B3LYP/6-311++G(d,p)/PCM-DCM. Table S1: Relative energies of anti and gauche conformers of $\mathrm{H}_{4} \mathrm{P}_{2}, \mathrm{Me}_{4} \mathrm{P}_{2}$, and $\left(\mathrm{CF}_{3}\right)_{4} \mathrm{P}_{2}$ systems at the B3LYP/6-311++G(d,p), M06-2X/6-311++G(d,p) and M06-2X/aug-cc-pVTZ computational level.

Acknowledgments: Adam D. Molloy thanks the UCD Centre for Synthesis and Chemical Biology for a Ph.D. Scholarship awarded under the Irish Higher Education Authority Program for Research in Third Level Institutions (HEA-PRTLI 4). Goar Sánchez-Sanz thanks the Human Frontier Science Program (Project Reference: LT001022/2013-C) for their support. We are grateful to the Irish Centre for High-End Computing (ICHEC) for the provision of computational facilities and support.

Author Contributions: Adam D. Molloy and Declan G. Gilheany conceived and designed the experiments; Adam D. Molloy and Goar Sánchez-Sanz performed the calculations. All authors analyzed the data, drew the conclusions and contributed to the writing the paper.

Conflicts of Interest: The authors declare no conflict of interest.

\section{References}

1. Maier, L. Direkt synthese von Alkyl-halogen-phosphinen. Angew. Chem. 1959, 71, 574-575. [CrossRef]

2. Mayer, L. Organische Phosphorverbindungen, I. Darstellung asymmetrischer Tetraalkyl- und Dialkyl-diaryl-diphosphindisulfide. Chem. Ber. 1961, 94, 3043-3050. [CrossRef]

3. Fluck, E.; Issleib, K. Untersuchungen der kernmagnetischen Resonanzspektren von Phosphorverbindungen, VIII: ${ }^{31}$ P-Resonanzspektren von Phosphinen, Biphosphinen und Biphosphindisulfiden. Chem. Ber. 1965, 98, 2674-2680. [CrossRef]

4. Lambert, J.B.; Mueller, D.C. The Inversion of Diphosphines. J. Am. Chem. Soc. 1966, 88, 3669-3670. [CrossRef]

5. Lambert, J.B.; Jackson, G.F.; Mueller, D.C. The stereochemical lability of diphosphines and diarsines. J. Am. Chem. Soc. 1968, 90, 6401-6405. [CrossRef]

6. Rauk, A.; Allen, L.C.; Mislow, K. Pyramidal Inversion. Angew. Chem. Int. Ed. Engl. 1970, 9, 400-414. [CrossRef]

7. McFarlane, H.C.E.; McFarlane, W. Intermolecular association of biphosphines. J. Chem. Soc. Chem. Commun. 1972, 1189-1190. [CrossRef]

8. Harris, R.K.; Norval, E.M.; Fild, M. Nuclear magnetic resonance studies of scrambling reactions in solutions of tetra-alkyl- and tetra-aryl-diphosphanes. J. Chem. Soc. Dalton Trans. 1979, 826-831. [CrossRef]

9. McFarlane, H.C.E.; McFarlane, W. Sign and magnitude of ${ }^{1} J(P P)$ in some biphosphines with bulky substituents. J. Chem. Soc. Chem. Commun. 1975, 582-583. [CrossRef]

10. Issleib, K.; Krech, K. Alkali-Phosphorverbindungen und ihr reaktives Verhalten, XXXI: Unsymmetrische Biphosphine des Typs $\mathrm{R}_{2} \mathrm{PPR}_{2}^{\prime}$. Chem. Ber. 1965, 98, 1093-1096. [CrossRef]

11. Cavell, R.G.; Dobbie, R.C. Preparation and properties of some bis(trifluoromethyl)-phosphorus and -arsenic derivatives containing P-P, P-As, and As-As bonds. J. Chem. Soc. A Inorg. Phys. Theor. 1968, 1406-1410. [CrossRef]

12. Avens, L.R.; Wolcott, R.A.; Cribbs, L.V.; Mills, J.L. Some perfluoroalkyl-substituted tripnicogens and their hydrolysis to yield chiral dipnicogens. Inorg. Chem. 1989, 28, 200-205. [CrossRef]

13. Avens, L.R.; Cribbs, L.V.; Mills, J.L. Reactions of secondary phosphines with a phosphorus-phosphorus bond and related reactions. Inorg. Chem. 1989, 28, 205-211. [CrossRef]

14. Avens, L.R.; Cribbs, L.V.; Mills, J.L. Exchange reactions of tetrakis(trifluoromethyl)diphosphine with pnicogen-pnicogen, phosphorus-hydrogen, and phosphorus-chlorine bonds. Inorg. Chem. 1989, 28, 211-214. [CrossRef]

15. Cowley, A.H. The chemistry of the phosphorus-phosphorus bond. Chem. Rev. 1965, 65, 617-634. [CrossRef]

16. Borisenko, K.B.; Rankin, D.W.H. P-P bond cleavage; energetics and structural changes in tetramethyldiphosphine and tetrasilyldiphosphine from ab initio MO calculations. J. Chem. Soc. Dalton Trans. 2002, 3135-3141. [CrossRef]

17. Balabin, R.M. Enthalpy difference between conformations of normal alkanes: Raman spectroscopy study of n-Pentane and n-Butane. J. Phys. Chem. A 2009, 113, 1012-1019. [CrossRef] [PubMed]

18. Durig, J.R.; DiYorio, J.S. Vibrational spectra and structure of organophosphorus compounds. VIII. Tetramethylbiphosphine. Inorg. Chem. 1969, 8, 2796-2802. [CrossRef]

19. Durig, J.R.; MacNamee, R.W. Raman spectra of gases. J. Mol. Struct. 1973, 17, 426-428. [CrossRef] 
20. Azofra, L.M.; Alkorta, I.; Elguero, J. Chiral discrimination in dimers of diphosphines $\mathrm{PH}_{2} \mathrm{PH}_{2}$ and $\mathrm{PH}_{2} \mathrm{PHF}$. ChemPhysChem 2014, 15, 3663-3670. [CrossRef] [PubMed]

21. Durig, J.R.; Shen, Z.; Zhao, W. Conformational stability, structural parameters, and vibrational frequencies from ab initio calculations for biphosphine. J. Mol. Struct. THEOCHEM 1996, 375, 95-104.

22. Becker, G.; Golla, W.; Grobe, J.; Klinkhammer, K.W.; Le Van, D.; Maulitz, A.H.; Mundt, O.; Oberhammer, H.; Sachs, M. Element-element bonds. IX.1 Structures of tetrakis(trifluoromethyl)diphosphane and -diarsane: Experimental and theoretical investigations. Inorg. Chem. 1999, 38, 1099-1107. [CrossRef] [PubMed]

23. Katsyuba, S.; Schmutzler, R. Comparative studies of geometric and quasielastic characteristics of PP and SS bonds. Dalton Trans. 2008, 1465-1470. [CrossRef] [PubMed]

24. Albrand, J.P.; Cogne, A.; Taieb, C. ${ }^{13} \mathrm{C},{ }^{1} \mathrm{H}$ and ${ }^{31} \mathrm{P}$ dynamic NMR studies of tetraalkyldiphosphanes: Barrier to internal rotation about the P-P Bond in tetraisopropyldiphosphane. Org. Magn. Reson. 1983, 21, 246-251. [CrossRef]

25. Cowley, A.H.; Dewar, M.J.S.; Goodman, D.W.; Padolina, M.C. Detection of rotational isomerism in diphosphines and diarsines by photoelectron spectroscopy. J. Am. Chem. Soc. 1974, 96, 2648-2650. [CrossRef]

26. Becke, A.D. Density-Functional Thermochemistry 3. The Role of Exact Exchange. J. Chem. Phys. 1993, 98, 5648-5652. [CrossRef]

27. Lee, C.T.; Yang, W.T.; Parr, R.G. Development of the Colle-Salvetti Correlation-Energy Formula into a Functional of the Electron-Density. Phys. Rev. B 1998, 37, 785-789. [CrossRef]

28. Møller, C.; Plesset, M.S. Note on an Approximation Treatment for Many-Electron Systems. Phys Rev. 1934, 46, 618-622. [CrossRef]

29. Frisch, M.J.; Pople, J.A.; Binkley, J.S. Self-Consistent Molecular-Orbital Methods 25. Supplementary Functions for Gaussian-Basis Sets. J. Chem. Phys. 1984, 80, 3265-3269. [CrossRef]

30. Reed, A.E.; Curtiss, L.A.; Weinhold, F. Intermolecular interactions from a natural bond orbital, donor-acceptor viewpoint. Chem. Rev. 1988, 88, 899-926. [CrossRef]

(c) 2016 by the authors; licensee MDPI, Basel, Switzerland. This article is an open access article distributed under the terms and conditions of the Creative Commons Attribution (CC-BY) license (http://creativecommons.org/licenses/by/4.0/). 